\title{
SOCIAL WORKERS' PERCEPTIONS OF INTER-ORGANISATIONAL COLLABORATION IN CHILD AND FAMILY WELFARE
}

\section{Madoda Sitshange}

\section{INTRODUCTION}

The nature of problems experienced by social workers' clients has often challenged social workers to collaborate with other organisations (Patel, Hochfeld, \& Selipsky, 2008). The concept of collaboration holds much promise, yet this delicate and complex process presents numerous risks of failure, threatening both the process of collaboration and the outcomes being sought. There are many barriers to inter-organisational collaboration. Consequently, there is a need for applicable knowledge and skills in the direct practice of partnership development in social development (Lombard \& Van Rensburg, 2001) - inter-organisational collaboration being one form of partnership development. This report explores and describes the concept of inter-organisational collaboration as a social service delivery strategy as very few guidelines exist that could assist in the planning and managing of collaborative partnerships ensuring that it achieves its intended aims and goals of delivering quality social services (Lombard \& Van Rensburg, 2001). A relevant theoretical perspective as presented here should inform the process of developing practice guidelines in collaborative approaches.

\section{THEORETICAL PERSPECTIVES FOR ANALYSING INTER- ORGANISATIONAL COLLABORATION}

A novice observer of partnership development that occurs across independent organisations would be intrigued by similar-sounding terms like collaboration, networks, coordination, task forces, coalitions and so on. The question arises: what are the main features of interorganisational collaboration that distinguish it from other forms of partnership development, and at what point it can be said that cross-agency interaction becomes a network, co-ordination or collaboration?

Harding and White (2002) especially identified the pooling of resources by different and autonomous organisations as one of the main characteristics of collaboration. The terms "interorganisational collaboration" and "collaboration" are used interchangeably in this article. The pooling of resources should result in the creation of a single organisational framework or structure, involving a dedicated project leader, shared or decentralised control and a common or joint budget. Compared to other forms of partnership development, "it is an intense form of mutual attachment" (Harding \& White, 2002:7).

As illustrated below, Lombard and Van Rensburg (2001) unpacked these similar-sounding concepts by using a continuum which considers networking as a lower level of interaction intensity, while collaboration reflects higher levels of interaction intensity. Related crossagency interactions such as co-ordination, establishing task forces and alliances in the middle of the continuum reflect medium levels of interaction intensity. 


\section{CONTINUUM OF PARTNERSHIP DEVELOPMENT}

$\begin{array}{ll}\text { Networking ....................... Coordination....................... Collaboration } \\ \text { Lower intensity } & \text { Moving into resources }\end{array}$

(Adapted from Lombard \& Van Rensburg, 2001)

This conceptualisation of cross-agency interaction points to the extent that different but related organisations blend their own people, structures and systems into a single and distinct structure to pursue common interests. Some definitions cluster together all related cross-agency concepts to the detriment of clear analysis. For instance, Abramson and Rosenthal (1995:1479) implied that "it is a group of independent organisations who are committed to working together for specific purposes and tangible outcomes while maintaining their own autonomy; they terminate their collaboration or transform themselves into other forms of organisations when that purpose is met. Such collaborations are variously referred to as coalitions, networks, strategic alliances, task forces or partnerships, each with its own characteristics". Accordingly, any cross-agency interaction can be called collaboration.

The concept of inter-organisational collaboration in theory and practice is not without its own potential problems and challenges. Others consider cross-agency collaboration as an idea and practice open to contradiction, successes and failure as, for instance, in practice, inter-agency relations can be characterised by conflict and competitive behaviour (Ferlie \& McGivern, 2003; Ospina \& Saz-Carranza, 2005). Scott (2003) identified four interrelated levels where potentially complex and protracted problems can appear, namely inter-organisational levels, intra-organisational, inter-professional and inter-personal levels.

The participants may be driven at an inter-personal level by a mix of incentives and ambitions; at the inter-professional level, by power relations; and at the inter-organisational and the intraorganisational levels by different "organizational meanings" that each may attribute to the collaborative (Ferlie \& McGivern, 2003). The concept of cross-agency collaboration can be a paradox, "a dynamic tension grounded in the coexistence of opposites" (Ospina \& SazCarranza, 2005:3). Hence, it is important that basic guidelines should exist or be established to mitigate the paradox around the process of collaboration amongst social welfare agencies in order to ensure that the application of social work methods in human relations will make a concrete contribution in making partnerships work.

\section{SOCIAL WORK METHODS}

Social work team members have an important role to play in this regard as "Research has shown that social work team members are more likely than other members to take active roles in helping the interdisciplinary team function effectively" (Middleman \& Wood, 1999:94). The existence of a knowledge and skills base, ranging from casework, group work, community development to social policy positions, allows social workers to optimally engage networks, coordinations and collaborations in the social development arena. The direct application of social work theory and skills in inter-organisational collaboration arrangements may furthermore present an opportunity to make an important contribution to the social development of families, communities and this country at large. Moreover, it may present a way to undo social workers' crisis of confidence in themselves and their profession, and make better use of their vital role in the area of social development (McKendrick, 2001). 
Paradoxically, this crisis of confidence is occurring at a time when most of the other necessary ingredients for social work to be a strong, vigorous player in social development are actually or potentially present: our profession has more knowledge and skills relevant to social development than any other; we have years of pertinent experience in working with people and environments; we have the largest organised workforce of all the social service professions - 10000 registered social workers; we have established agency structures that can be adapted towards developmental enterprises; we have new opportunities for funding - the programme structure - that cry out for exploitation; and we have a government policy that for the first time in many years is in harmony with our deepest professional beliefs of social justice and equity (McKendrick, 2001:105).

Social work as a profession promises to add value to partnerships by bringing in abstracts and concepts, as well as relational, emotive, affective and human skills to enhance the combining of human and material resources for social action (Middleman \& Wood, 1999).

\section{THE WHITE PAPER FOR SOCIAL WELFARE (1997)}

The White Paper for Social Welfare (1997) represents a milestone in the South African welfare system. This white paper sought to address racial disparities in the allocation of welfare services by redistributing resources based on social rights and equity (Patel, 2003). "In this White Paper the National Developmental Social Welfare strategy is based on the principle of non-discrimination, which states: 'Social Welfare services and programmes will promote nondiscrimination, tolerance, mutual respect, diversity and inclusion of all groups in society. Women, children, the physically and mentally disabled, offenders, people with HIV/AIDS, the elderly, and people with homosexual or bisexual preferences, will not be excluded"' (Keevy \& Alpaslan, 2001:114-115). Three key principles behind the White Paper for Social Welfare directly relate to the collaborative approach in the delivery of social services, namely partnerships, inter-sectoral collaboration and decentralisation.

\section{CHILD AND FAMILY WELFARE}

Social welfare, which includes child and family welfare, is a broad concept that is defined "as a system of laws, programs, benefits and services which strengthen or assure provision of meeting social needs recognised as basic for the welfare of the population and for the functioning of the social order" (Friedlander \& Apter, 1980:4). In 1996 a Committee of the Minister of Welfare and the Provincial Members of the Executive Council established the Lund Committee on Child and Family Support (henceforth referred to as the Committee) (Lund Committee, 1996). The Lund Committee was obliged to undertake a critical appraisal of the existing system of state support to children and families, and to develop approaches for effective targeting of socio-economic development programmes for children and families. The Committee presented a new policy paradigm that deviated from the nuclear family preservation policy underlying to the welfare policy of the past, since most poor households are extended families (Vorster \& Roussouw, 1997). According to Vorster and Roussouw (1997), the Lund Committee shifted the focus from the family model to a plan modelled around a central theme of "follow the child", balanced with family preservation. The Committee strongly recommended comprehensive inter-sectoral collaboration on programmes aimed at the relief and eradication of poverty, particularly within the health, education and early childhood development sectors. The vision of the current welfare dispensation is to have a redistributive impact by shifting limited resources to poor households and protect the poorest children in the 
most vulnerable years; moreover, child protection services are shifting from a rights-based approach to integrated family-centred and community-based services as one of the key features of the developmental welfare service delivery model (Lombard, 2008; Louw, 1998; Patel, 2005).

\section{PARTNERSHIP DEVELOPMENT: A SERVICE DELIVERY STRATEGY}

Best practice models informed by empirical research about collaboration as a special area of study need to be formulated in the South African context, as human and material resources need to be pooled for agents of development to have a maximum impact on social problems. According to Lombard and Van Rensburg (2001), the process of partnership development has to be informed by guidelines for efficiency and effectiveness purposes. An evidence-based approach to collaborative work needs to be consciously linked with strategies aiding the implementation of the White Paper for Social Welfare. The social workers' perceptions of the concept of collaboration is therefore pertinent to distinguish this form of partnership from networks, co-ordinations and other forms of partnerships to keep the focus on the level of interaction needed to impact more on social problems.

\section{RESEARCH DESIGN AND METHOD}

The research design informing this report was constructed as an exploratory-descriptive design with an interview schedule. This design was chosen to provide the researcher with a suitable means to obtain information about the phenomenon chosen for the study to supplement the researcher's limited knowledge of it (Mouton, 1996). Twenty-five social workers practising in the field of child and family welfare were randomly selected to participate in the research. Stratified random sampling was used in order to obtain a cross-section of social workers at various levels in the organisations where they were employed, from social workers to managers. Social workers with a minimum of twelve months to a maximum of three years of partnering with other agencies were interviewed on a face-to-face basis about their experience.

\section{RESEARCH TOOL}

The interview schedule comprised closed- and open-ended questions. The design of the research tool was guided by utilisation of the major theoretical constructs concerning the research topic and the literature on inter-organisational collaboration (Neuman, 1997). The interview schedule was subjected to a pilot study with two social workers who had experience in working with other organisations and the interview schedule was modified accordingly.

\section{DATA ANALYSIS}

Thematic content analysis was used to extract themes and categories for the analysis of qualitative data. The quantitative data were analysed in a descriptive form, resulting in similar responses being grouped together; data were presented in a quantitative form (Mouton, 1996).

\section{FINDINGS AND DISCUSSION OF RESULTS}

The researcher interviewed 25 social workers working in the field of child and family welfare and focused on their perceptions regarding inter-organisational collaboration. The profile of the participants was as follows: $40 \%$ participants were employed in the public sector, while $32 \%$ represented the non-governmental sector, and $28 \%$ participants were in private practice. The non-governmental sector represented a wide-ranging number of private, voluntary and selfgoverning not-for-profit bodies and organisations serving the public interest in child and family welfare services through government subsidies or private funding (Lombard \& Van Rensburg, 
2001). About $72 \%$ of participants identified their professional title as either manager/chief/senior social worker, while $28 \%$ identified themselves as social workers. This pattern demonstrated that social workers in senior positions are more likely to participate in partnership activities, as compared to social workers in junior positions. The participants' age ranged between 27 and 62 years, with a mean age of 38 years. At some point in their professional social work practice experience all 25 respondents were directly involved in partnerships with other organisations for at least a minimum period of twelve months to a maximum of three years.

\section{THE PARTICIPANTS' KNOWLEDGE AND UNDERSTANDING OF THE NATURE AND PURPOSE OF COLLABORATION}

All 25 participants were of the opinion that inter-organisational collaboration referred to a longterm formal relationship, a key feature highlighted by Winer and Ray (1996) and Reilly (2001), who maintained that inter-organisational collaboration is a more durable relationship, where the level of formalisation is more than that observed in networks, cooperatives and coordination. Theory suggests that networks and cooperatives are generally short-term structures in nature, while collaborations are more formal in that their chief feature is a formal longer-term structure (Alter \& Hage, 1993; Lombard \& Van Rensburg, 2001; Winer \& Ray, 1996).

On the issue of where authority lies in collaborative structures, $100 \%$ of participants believed that authority should rest with all the representatives of the different organisations, although most said sharing control in reality was far more complex. In the main, this finding is supported by Mullen (2008), who said that all partners need to be stakeholders and exercise some degree of authority in order to be able to take risks and be more motivated to dedicate resources. A considerable majority of $80 \%$ of the participants believed that in a collaboration resources should be kept separate, a finding which contradicted assertions by Harding and White (2002), which identified the ability of partners to pool resources as one of the defining features in a collaboration relationship. This particular finding was inconsistent with the literature; what was consistent was that $20 \%$ of participants confirmed the stance in the literature concerned by disagreeing that resources should be kept separate in collaborations (Abramson \& Rosenthal, 1995; Alter \& Hage, 1993).

About $80 \%$ of the participants agreed that collaborating organisations should keep their respective identities separate, while $20 \%$ disagreed on that particular issue. The finding that organisations should keep their separate identities is implausible, according to Reilly (2001), who indicated that individual agencies pool resources to form a new structure, thus forming a new identity as a distinct structure.

Asked what motivated their participations in collaborations, $100 \%$ of the participants maintained that policy directives lead them to be involved in collaborations, thereby corroborating assertions that policies such as the Financial Policy for Developmental Social Welfare (1999) were most significant in motivating social workers to establish partnerships in the social welfare sector (Lombard \& Van Rensburg, 2001). The data further indicated that $72 \%$ of participants said that the legal framework as represented by the current legislation (White Paper for Social Welfare, 1997) gave a rationale for them to partner with social workers from other organisations, while $28 \%$ of participants disagreed with the suggestion that they collaborated because of legal mandates.

All participants (100\%) agreed on two main purposes of inter-organisational collaboration, namely the focus on the need to leverage resources and, as a result, to achieve sustainable 
change. The findings overlap with Reilly's (2001) stance that collaborations exist for the purpose of building power/capacity to impact meaningfully on protracted social problems. Mullen (2008) and Ospina and Saz-Carranza (2005) described the main purpose of collaboration as being to bridge organisational gaps that prevent social services organisations from having a maximum impact on massive social problems.

It should be noted that no participant attended any formal training in developing partnerships their knowledge and understanding was sourced mainly from practice experience. It can be deduced from the data that formal training of social workers in the area of partnership development appear not to be widespread in the Gauteng area, a factor requiring further investigation.

\section{PARTICIPANTS' PERCEPTIONS OF FACTORS THAT FACILITATED COLLABORATION}

A majority $(80 \%)$ of participants said having an enhancing socio-political environment was very important in compelling them to engage other organisations in the field of child and family welfare, primarily to have more impact in delivering services to clients; $20 \%$ of participants maintained that a friendly socio-political environment was of average importance in making it a duty to collaborate with other agencies within the child and family services. The overall findings on this statement corroborate Clark's (1992) and Sewpaul's (2001) emphasis on identifying legislation and financial policies, such as the White Paper for Social Welfare (1997), as being vital in creating a favourable socio-economic climate for collaborations to be supported. The policies, however, do not provide guidelines on how to establish and maintain partnerships (Lombard \& Van Rensburg, 2001), an apparent gap between policy and practice.

About $84 \%$ of participants stated that having a good cross-section of members or stakeholders was very important in encouraging them to participate in collaborations with other organisations, $16 \%$ were neutral in their response by maintaining that a good cross-section of stakeholders was of average importance in compelling them to engage other agencies in collaborations. About $96 \%$ of participants were involved in collaborations because this facilitated communication between organisations, whilst $4 \%$ of participants thought this factor (communication) was of average importance.

Altogether $60 \%$ of participants said issues of mutual respect and trust were of average importance in motivating them to enter into collaborations, while $40 \%$ maintained that issues of respect and trust were very important in facilitating their involvement in inter-organisational collaboration. Alter and Hage (1993) believe that trust and mutual respect have the capacity to draw stakeholders into participating in collaborations on a longer-term basis, as they don't avoid, but rather deal directly with difficult questions of actual or perceived inequities, prejudice and stereotypes that can threaten the very survival of partnerships. Respect and trust, therefore, are associated with addressing stereotypes and inequities, especially within a social welfare system that evolved from a past of racial discrimination and apartheid (McKendrick, 1990; Patel, 1992).

\section{PARTICIPANTS' PERCEPTIONS OF FACTORS HINDERING INTER- ORGANISATIONAL COLLABORATION}

According to Smock (1999) and Alter and Hage (1993), regular dissemination of information about policies, regulations and protocol keep collaborations on track, an observation confirmed by only $20 \%$ of participants who maintained that failure to communicate vital information was 
a hindering factor in collaborations. Most of the participants, $80 \%$ in number, thought collaborations could not be hampered by failing to communicate policies and programmes of action to key stakeholders, a finding refuted by theory.

The participants were divided into two nearly equal numbers on whether cultural differences among the stakeholders could hinder in some way inter-organisational collaboration, with 52\% of participants confirming that differences in culture hampered collaborations among agencies, while $48 \%$ of participants did not consider cultural differences as critically important in hindering collaborations, suggesting lack of general consensus on this specific theme. Cultural differences in the child and family welfare sector and the role they play need to be investigated further because of the history of racially exclusionary policies and fragmented welfare services (McKendrick, 2001; Patel, 2003). Partnerships based on a shared vision and a common identity need to be formed to allocate resources where they are needed the most. In such a case the intention should be for cultural differences not to be a stumbling block to effective collaboration, as no single social welfare institution can solve social problems unilaterally.

Nearly all the participants, namely $92 \%$ of them, indicated that lack of trust among the stakeholders was a critical barrier to collaboration between organisations, while $8 \%$ of the participants were neutral on this particular matter. The competition (for resources, clients, prestige, authority) among the stakeholders was considered by a majority of $80 \%$ as one of the important barrier to inter-organisational collaboration, while $20 \%$ participants were neutral on the theme of competition between stakeholders.

A high number of $80 \%$ participants thought inter-organisational collaboration was hindered by the conflicting agendas of the stakeholders, a barrier that was considered a high risk. On the other hand, $20 \%$ of participants maintained that conflict agendas were insignificant in posing a barrier to inter-organisational collaboration. The main findings overlap with Winer and Ray's (1996) assertion that conflicting agendas present a serious barrier to parties from having a common vision. In inter-organisational collaboration in this context, a common vision should be like a glue that should hold them together while navigating the complex process of collaboration. Partnerships can fall apart should conflicting agendas linger without resolution. Skills and approaches to align the stakeholders' agendas need to be examined to minimise threats to partnering across agencies.

All 25 participants were in agreement that lack of leadership was an important factor that can undermine collaboration across different organisations. As far as this is concerned, Winer and Ray (1996) pointed out that competent and effective leadership is the driving force behind successful collaboration.

All participants $(100 \%)$ were unanimous in indicating that in their view lack of concrete results was one of the most significant barriers to inter-organisational collaboration. Clearly a lack of concrete and tangible results will discourage any agency in most instances from investing time, money and personnel on fruitless initiatives. Scarce and limited resources cannot be wasted while social problems continue to undermine the quality of child care and family life. The process of pooling resources from different organisations is not an end in itself (Clark, 1992; Mullen, 2008); the ultimate goal is to impact on social problems in a meaningful and sustainable way, something that the participants have not observed as far as their response to this statement seems to suggest. The ability to secure concrete results would draw people into collaborations, while the lack of results may frustrate people to the extent that they may not want to participate in partnerships. The attainment of outcomes is associated with the way a 
partnership is managed, an area to which more research can contribute, to improve the quality of child and family services (Oxfam, 2007).

A majority of $92 \%$ participants perceived all or most of the hindering factors as stressful issues that could exceed their coping capabilities and no suggestions were forthcoming in dealing with that challenge; $8 \%$ of participants said hindering factors were challenges that forced them to grow and develop skills and new approaches in dealing with partners from other organisations.

\section{CONCLUSION AND RECOMMENDATIONS}

The researcher achieved the objectives of exploring and describing the concept of interorganisational collaboration as perceived by the research participants. What emerged from the research was that social workers' perceptions of collaboration in the child and family welfare sector were at times consistent with theory, at times inconsistent. The need that was raised by the research participants was for structured benchmarks, assessment tools and models to be developed to improve the way social workers integrate resources, with a view to impacting on social problems over the longer term, especially in the field of child and family welfare. These tools could then be used to address inconsistencies that can undermine the collaboration process.

The social work professions' skills and knowledge base in human relations is a relevant resource that can add value to multi-sectoral collaboration, ensuring partnership efforts have a lasting impact on protracted social problems. Schools of social work, social development research institutions, government departments, non-governmental organisations and private practitioners have a role in motivating and supporting social workers to create and nurture effective partnerships. Competencies in casework, group work, community development, social policy formulation and scientific research can therefore be used to close the gap between policy and implementation, as far as partnership development as an implementation strategy is concerned. The problems and challenges in getting people to work together across agencies cannot be denied, while the need to use inter-organisational collaborations to effect social change cannot be overlooked. The question should be how to make collaborations benefit more children and families in need of social services.

It is recommended that the most significant aspects of partnership development should be investigated further to inform theory, policy and practice in this special area of interest. The experiences of social workers in this regard since the early 1900 s need to be explored and described in more detail through research in order for social workers to learn from past challenges and to be better prepared for and enabled to form such partnerships. Quantitative and qualitative research is recommended at national, provincial and local levels of social services formulation and provision.

It is recommended that training be supplemented with ongoing consultation, from the inception of a specific collaboration to its termination (if applicable). The aim should be for all stakeholders to be supported to deal with challenges, problems and dynamics that can result from stakeholder interaction, for hindering factors to be minimised and enabling factors to be enhanced. Professional consultation, combined with skills training, research, documentation and publishing, is recommended to provide intellectual capital for social workers to build their capacities in areas of networking, coordination and collaboration.

In this regard need for the development of relevant theory should be noted. A theory is a presumption, a set of concepts and ideas that is intended to describe a certain phenomenon 
(Neuman, 1997). It is recommended that suitable theory be development in the area of child and family welfare partnership from a social work perspective. Social work as a human services profession is concerned with enhancing the way that people interact with their social environment (Ganter \& Yeakel, 1980) - a theoretical orientation needs to be developed relating to the area of best practice in partnership development. The challenge is essentially around aligning social work theory to have more relevance to multi-sectoral collaboration at the point of service delivery.

It is further recommended that research be conducted into how other professionals in human services organisations manage multi-sectoral collaboration. For instance, learning from psychologists, nurses, occupational therapists, doctors, sociologists, lawyers, community development practitioners and other relevant stakeholders about their accumulated knowledge and practice experience should assist in improving partnerships in social work.

Inter-organisational collaboration is a process to achieve an outcome. Social services organisations across South Africa have an ongoing challenge of developing creative solutions that address the needs of many, while securing the needs of the few.

The transformation of the social welfare system should go beyond only bringing together resources, but should also focus on facilitating relationships based on openness, trust and an understanding that complex issues require a common vision, joint activities and a commitment to resolving issues.

Collaboration across social welfare organisations in the South African context must be based on the humanist philosophy of ubuntu, an ethical orientation focused on people's allegiances and relations with each other. Ubuntu and inter-organisational collaboration speak about our inter-connectedness, particularly the fact that most social problems cannot be solved in isolation (Louw, 1998).

\section{REFERENCES}

ABRAMSON, J.S. \& ROSENTHAL, B.B. 1995. Interdisciplinary and interorganizational collaboration. In: Encyclopedia of Social Work $\left(19^{\text {th }}\right.$ ed), Issue 2. Washington, DC: NASW Press.

ALTER, C. \& HAGE, J. 1993. Organizations working together. London: Sage Publications. CLARK, R.W. 1992. Evaluating the collaboration process: building coalitions. The Ohio State University Extension.

FERLIE, E. \& McGIVERN, G. 2003. Relationships between health care organisations: a critical overview of the literature and a research agenda. A report for the National Coordinating Centre for NHS Service Delivery and Organisation R \& D (NCCSDO). Centre for Public Services Organisations: The Business School. Imperial College, London.

FRIEDLANDER, E.A. \& APTER, R.Z. 1980. Introduction to social welfare. Englewood Cliffs, New Jersey: Prentic-Hall.

GANTER, G. \& YEAKEL, M. 1980. Human behaviour and the social environment: a perspective for social work practice. New York: Columbia University Press.

HARDING, O. \& WHITE, L. 2002. Collaboration within a health action zone project- a case study. A report for the LSL HAZ. London. 
KEEVY, C. \& ALPASLAN, A.H. 2001. A needs assessment for a relationship-guidance programme for partners in a gay male relationship. Social Work/Maatskaplike Werk, 37(2):113-124.

LOMBARD, A. 2008. The implementation of the white paper for social welfare: a ten-year review. The Social Work Practitioner-Researcher, 20(2):154-173.

LOMBARD, A. \& VAN RENSBURG, J.A. 2001. Coalitions: a practice framework for sustainable development. Social Work/Maatskaplike Werk, 37(4):325-342.

LOUW, L.R. 1998. Changing social welfare policy in South Africa. Social Work/Maatskaplike Werk, 34(1):134-143.

LUND COMMITTEE 1996. Report of the Lund Committee on Child and Family Support. Pretoria: Government Printer.

McKENDRICK, B.W. 1990. The future of social work in South Africa. SocialWork/Maatskaplike Werk, 26(1):10-18.

McKENDRICK, B.W. 2001. The promise of social work: directions for the future. Social Work/Maatskaplike Werk, 37(2):105-112.

MIDDLEMAN, R.R. \& WOOD, G.G. 1999. Skills for direct practice in social work. New York: Colombia University Press.

MOUTON, J. 1996. Understanding social research. Pretoria: Van Schaik Publishers.

MULLEN, J. 2008. Best practices in inter-organizational collaboration: a how to manual for organizations working to integrate services for persons with ASD and their families. A project of The California Department of Developmental Services.

NEUMAN, W.L. 1997. Social research methods: qualitative and quantitative approaches. London: Allyn and Bacon.

OSPINA, S. \& SAZ-CARRANZA, A. 2005. Paradox and collaboration in coalition work. A paper prepared for presentation at the 2005 Annual Meeting of the Academy of Management, "A New Vision of Management In The $21^{\text {st }}$ Century", August 5-10, Honolulu, Hawaii.

OXFAM. 2007. Case study on the Phelang Community Centre: facilitating multi-sectoral collaboration in Limpopo, South Africa. A series of reports on the Joint Oxfam HIV and AIDS Program (JOHAP). Oxfam International: Case study No. 05.

PATEL, L. 1992. Restructuring social welfare: options for South Africa. Johannesburg: Ravan Press.

PATEL, L. 2003. Social development in a society in transition. Working Paper No. 03-18. Center for Social Development: George Warren Brown School of Social Work. Washington: Washington University in St. Louis.

PATEL, L. 2005. Social welfare and social development in South Africa. Cape Town: Oxford University Press.

PATEL, L., HOCHFELD, T. \& SELIPSKY, L. 2008. The implication of the White Paper for Social Welfare in the NGO sector. Johannesburg: Centre for Social Development in Africa, University of Johannesburg.

REILLY, T. 2001. Collaboration in action: an uncertain process. Administration in Social Work, 25(1):53-74.

Social Work/Maatskaplike Werk 2012:48(2) 
SCOTT, D. 2003. Collaboration: a few reflections. Australian Research Alliance for Children and Youth: Strategic Directions Meeting for Members, 8 December 2003.

SEWPAUL, V. 2001. Economic globalisation and social policy reform: social work curricula in the South African context. Social Work/Maatskaplike Werk, 37(4):309-324.

SMOCK, K. 1999. Building effective partnerships: the process and structure of collaboration. [Online] Available: http://www.nhi.org/online/issues/105/smock.html. [Accessed: 04/09/2002].

VORSTER, J. \& ROSSOUW, H. 1997. Transforming state support for children and families in South Africa: single mother households footing the bill. Social Work/Maatskaplike Werk, 33(4):315-332.

WHITE PAPER FOR SOCIAL WELFARE. 1997. Government Gazette, 386 (18166). Pretoria: Government Printer.

WINER, M. \& RAY, K. 1996. Collaboration handbook: creating, sustaining, and enjoying the journey. Melbourne: Victorian Health Promotion Foundation.

Mr Madoda Sitshange, Social Work Practitioner, Pretoria, South Africa 